\title{
Disc embolisation after minor strut fracture in a Björk-Shiley mitral valve prosthesis
}

\author{
B SETHIA, RO QUIN, WH BAIN \\ From the Department of Cardiac Surgery, Western Infirmary, Glasgow; and Gartnavel General Hospital, \\ Glasgow
}

We report the successful management of a patient who suffered embolisation of a Björk-Shiley mitral prosthetic valve disc after fracture of the minor strut. Emergency surgical treatment was responsible for her survival. The disc was recovered through the abdominal aorta at a subsequent operation, performed once the condition of the patient had stabilised. This experience confirms previous reports $^{12}$ advocating early reoperation in patients with Björk-Shiley prostheses who present with acute heart failure and absence of prosthetic valve sounds. We suggest that retrieval of the embolised disc may be carried out separately as an elective procedure provided that there is no evidence of renal or peripheral circulatory impairment.

\section{Case report}

A 36-year-old woman underwent closed mitral valvotomy in 1975 for relief of tight mitral stenosis. She remained well for the next five years but then complained of increased tiredness and dyspnoea. Physical examination suggested renewed mitral stenosis and this was confirmed by echocardiography and cardiac catheterisation. She underwent mitral valve replacement in February 1982 with a 31-mm Björk-Shiley concavo-convex prosthesis; her postoperative course was uneventful and she was able to resume virtually normal activities.

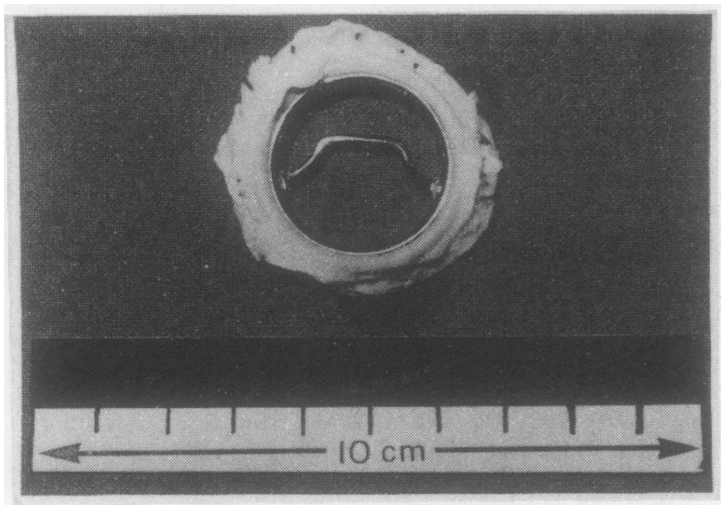

Fig 1 The excised Björk-Shiley prosthesis.

Address for reprint requests: Mr B Sethia, Department of Cardiac Surgery, Western Infirmary, Glasgow G11.

Accepted 3 February 1983
On 17 October 1982 she was admitted as an emergency complaining of faintness of acute onset some six hours previously, accompanied by worsening dyspnoea. She had also noticed the sudden disappearance of her prosthetic valve sounds. On examination she was orthopnoeic and her peripheries were cool. Her pulse rate was 146 beats per minute with atrial fibrillation and her blood pressure was $75 / 40 \mathrm{~mm} \mathrm{Hg}$. The heart sounds were faint and the prosthetic valve sounds were absent. There were no murmurs. Her thrombotest value was $15 \%$ and radiological screening failed to identify the mitral valve disc.

On account of her deteriorating condition she was taken to the operating theatre and placed on cardiopulmonary bypass. When the left atrium was opened there was no evidence of thrombus. The prosthetic valve disc was absent and the minor strut was found to have broken off. Despite careful palpation this was not felt anywhere within the left ventricle but after operation was noticed to be embedded in the left ventricular wall at the apex. The remaining prosthesis was excised (fig 1) and the valve replaced with a 31-mm Björk-Shiley concavo-convex prosthesis with integral struts. At the end of the procedure the condition of the patient was stable and with further screening before she left the operating theatre the valve disc was identified in the abdominal aorta at the level of L1 (fig 2). As the lower limb pulses were present and there was no evidence of renal impairment no attempt was made to remove the disc at this stage.

The postoperative course was uneventful and five days later the patient had the disc removed at laparotomy. She also underwent cholecystectomy at the same operation. She was discharged home 12 days after admission and was well when first reviewed in the outpatient clinic.

\section{Discussion}

Embolisation of a prosthetic disc or ball occluder is usually fatal unless emergency valve replacement is undertaken..$^{1-3}$ To our knowledge this is the first reported case in which fracture of the minor strut of a Björk-Shiley mitral valve prosthesis resulting in embolisation of the pyrolite carbon disc has been treated successfully. The occurrence in our patient of acute heart failure coupled with her own observation that prosthetic valve sounds were absent facilitated the diagnosis of disc embolisation. We believe that the inertness of the pyrolite carbon disc assisted the recovery of the patient from emergency valve replacement by reducing the risk of thrombosis before the subsequent removal of the disc. Although recent 390 


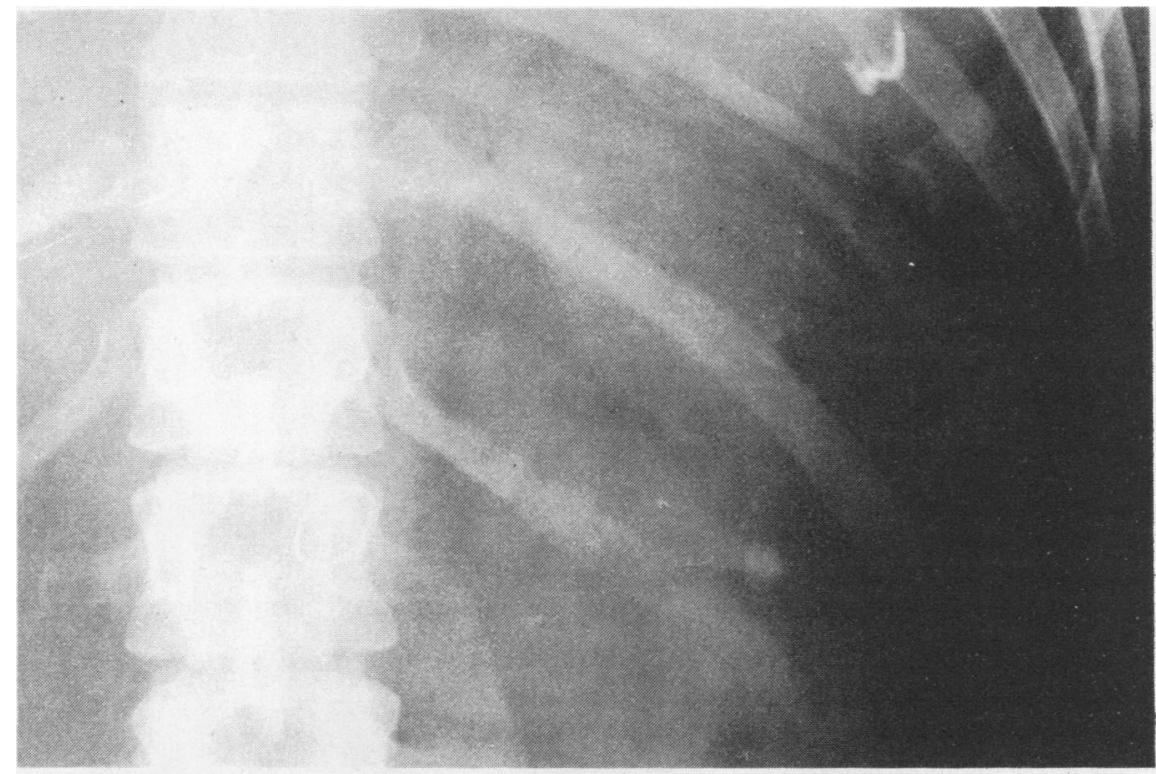

Fig 2 Plain abdominal radiograph showing the valve disc in the descending aorta; note the portion of minor strut embedded in the left ventricle.

modifications may improve the durability of the Björk-Shiley mitral valve, the occurrence of disc embolisation should always be suspected when sudden clinical deterioration occurs in a patient with a mitral valve prosthesis. We agree with the recent suggestion ${ }^{1}$ that surgical removal of the disc can be more safely achieved once the condition of the patient is stable.

\section{Addendum}

Since this paper was submitted for publication we have had one further case of fracture of the minor strut in a BjörkShiley mitral valve prosthesis. The patient presented as an emergency with acute pulmonary oedema 10 months after insertion of a concavo-convex Björk-Shiley mitral valve prosthesis. He had previously been well, and the character of his valve click had altered on the day of admission. At emergency operation the mitral valve prosthesis was excised and replaced with a 29-mm Carpentier Edwards xenograft. His initial postoperative course was satisfactory and he was extubated four days after surgery; but he developed intractable respiratory complications, septicaemia, and hepatorenal failure and died nine days after emergency surgery. At necropsy there was no evidence of infection on the newly inserted valve or on the disc in the abdominal aorta.

\section{References}

' Larrieu AJ, Puglia E, Allen P. Strut fracture and disc embolisation of Björk-Shiley mitral valve prosthesis: localisation of embolised disc by computerised axial tomography. Ann Thorac Surg 1982;34:192-5.

${ }^{2}$ Hughes DA, Leatherman LL, Norman JC, Cooley DA. Late embolisation of prosthetic mitral valve occluder with survival following re-operation. Ann Thorac Surg 1975;19:212-5.

${ }^{3}$ Ansbro J, Clark R, Gerbode F. Successful surgical correction of an embolised prosthetic valve poppet. $J$ Thorac Cardiovasc Surg 1976;72:130-2. 